\title{
A prospective long term observational clinical study to evaluate the significance of manual tooth brushing on gingival recession
}

Esam Dhaifullah ( $\square$ dhaifullah02@gmail.com )

https://orcid.org/0000-0002-7552-6862

koppolu Pradeep

Dar Al Uloom University College of Medicine

Butchibabu Kalakonda

Alfarabi

Esam Elkhatat

Al-Farabi College

Research article

Keywords: Gingival recession, Modified Stillman tooth brushing technique, Toothbrushing frequency

Posted Date: May 11th, 2020

DOI: https://doi.org/10.21203/rs.3.rs-21593/v1

License: (c) (i) This work is licensed under a Creative Commons Attribution 4.0 International License. Read Full License 


\section{Abstract}

\section{Purpose:}

Gingival recession (GR) is a common finding in adult populations associated with varied etiologies. The aim of our study was to correlate the influence of tooth brushing on GR. Further, it was intended to evaluate the role of a corrective tooth brushing technique with proper oral hygiene instructions on progression/regression of GR on a long term (3 years) follow up.

\section{Methods:}

A total of 53 healthy subjects, male and female, 18 to 52 years of age, without any boneloss were examined. A questionnaire evaluated all the variables associated with tooth brushing in these subjects. Later, patients were instructed on Modified Stillman brushing technique and oral hygiene instructions were reinforced. All the parameters were measured by two trained calibrated examiners at the baseline and at 6 month intervals.

\section{Results:}

Majority of the subjects with GR at the first visit used hard toothbrush bristle (62.2\%), brushed their teeth twice daily (56.7\%) and did not know the correct technique of tooth brushing (83.1\%). Those subjects with buccal recession evident in the first visit who maintained high standard of oral hygiene as per our instructions and had followed the correct brushing technique as advised, it was observed that GR progressed only at the following teeth: the first and second right mandibular premolars, right mandibular canines, left mandibular canines and first left maxillary molars (total 17. 9\%).

\section{Conclusion:}

The results of our study validate that the various variables associated with tooth brushing such as type of tooth brush, type of tooth brushing technique and frequency of tooth brushing have a potential role that result in GR. Moreover, a correct tooth brushing technique together with good oral hygiene prevents further recession.

\section{Introduction}

Gingival recession (GR) has been defined as the exposure of the root surface due to an apical shift of the gingival margin. ${ }^{18,21} \mathrm{GR}$ poses a myriad of problems that range from exposure of root vulnerable to root caries and dentine hypersensitivity and also results in an unaesthetic appearance of the teeth, a major concern for young adult population. ${ }^{17,1}$

Various etiological factors have been cited as causative factors for GR. The predominant causative factor however is dental plaque resulting in inflammation of the gingiva. ${ }^{27,25}$ Other risk factors include 
traumatic tooth brushing habits, iatrogenic dental procedures, smoking, ageing, malpositioned teeth, and high frenal and muscle attachments which have contributed to GR. $4,10,11,14,19$

There have been many epidemiologic studies related to the prevalence and occurrence of recession among various representative populations of the world and most of these populations had a prevalence of $50-90 \% .^{3}$ Data from these studies suggest that the prevalence of GR appeared to be proportional to age, with lower prevalence in younger individuals compared to their older counterparts.

Many observational studies that emphasized the role of traumatic tooth brushing in the etiopathogenesis of GR presented ambiguous results. These studies considered various factors associated with tooth brushing such as use of manual and electric tooth brushes, tooth brush stiffness, frequency of tooth brushing and the type of brushing technique as causative factors for GR but were of short duration and were inconclusive. ${ }^{8,2}$ It was evident that people with high standard of oral hygiene associated with tooth brushing had loss of attachment and marginal tissue recession predominantly at buccal surfaces. ${ }^{2,18,24}$ Further, there is dearth of studies on the prevalence of recession and the influence of correcttooth brushing technique and maintenance of good oral hygiene on progression/regression of GR on a long term follow up.

Hence, the aim of our present study was to evaluate the presence of GR in a population sample and identify the influence of tooth brushing on GR. Further, it was intended to evaluate the influence of a correct brushing technique and high standard of oral hygiene onprogression/regression of gingival recession in a select population attending the Outpatient Department of Periodontics, Al Farabi college.

\section{Material And Methods}

The study was carried out on the out patients who visited the Department of Periodontics, Al Farabi college, Riyadh from October 2014 to October 2017. An observational study was carried initially to assess the prevalence of GR and the influence of oral hygiene. Based on these findings a representative sample size was arrived at and a total of 53 subjects were recruited through a random sampling procedure. The subjects included 33 females and 20 males aged between 18 and 52 years with a mean age of $36.9 \pm$ 8.14 years.

The study was reviewed and ethical approval was taken from the institutional review board. All the participants were apprised of the study protocol and a written informed consent taken from every participant.

A pre-tested questionnaire was prepared with knowledge based from the short observational study. Information from all the subjects was collected prior to the clinical examination. The questionnaire comprised of questions related to age, gender, smoking history and oral hygiene habits (i.e. type of toothbrush used, frequency of brushing, method of brushing, duration of the use of toothbrush).

\section{Inclusion and exclusion criteria:}


All subjects who had a minimum of 20 permanent teeth present in proper occlusion and who presented with good general and periodontal health were included in the study. Subjects with factors that contributed to GR such as high frenal attachment, maligned teeth, inadequate width of attached gingiva and shallow vestibule were excluded from the study. Subjects, who were smokers, currently receiving orthodontic treatment,who underwent any dental treatment in the last 6 months, were also excluded.

All the subjects were informed about the study protocol (considering it a long term study) and those participants who gave their voluntary informed consent were included in the study.

\section{Clinical examination:}

The subjects who participated in the study underwent a thorough clinical examination by two well trained calibrated examiners in a dental chair using a set of periodontal diagnostic instruments comprising of the mouth mirror, explorer and a William's periodontal probecalibrated up to $10 \mathrm{~mm}$.Prior to the commencement of the study, both the examiners underwent training exercises on a group of patients and calibration was performed. The training exercises to validate the reliability of the examiners were undertaken for about four days until an intra class correlation coefficient of $0.85 \mathrm{k}$ was obtained, which was deemed satisfactory.

Intraoral radiograph or OPG examination were advised by which the alveolar bone level was assessed so as to eliminate subjects with bone loss.

GR was recorded using Miller's classification of GR.Other clinical parameters recorded were Papillary bleeding index (PBI) by Muhlemman and modified Quigley and Hein $(\mathrm{Q}-\mathrm{H})$ index.

After the examination, each patient received oral hygiene instructions and was motivated to maintain their oral health. Each patient was instructed to use a vertical-rotatory brushing technique (Modified Stillman) with a soft bristle toothbrush and with a tooth brushing frequency two times daily. Assessment of GR was performed after gingivitis was eliminated (the accepted score of Papillary bleeding index by Muhlemman for each patient must be $\leq 15$ ).

During examination for $\mathrm{GR}$, the teeth were divided into three dental sites from the buccal aspect(mesial,mid-buccal and distal) and generally the deepest point of mid-buccal surfaces of all the teeth excluding third molars was measured in millimeters as the distance from the cement-enamel junction (CEJ) to the free gingival margin. The primary concern however is, in certain areas the location of the CEJ was distorted either due to dental caries, restorations or crowns. Then the location of the CEJ was done arbitrarily considering the position of the CEJ on the adjacent tooth and the measurement of GR was done. The measurements were rounded off to the nearest whole millimeter. Recession was considered positive and recorded if there was more than $1 \mathrm{~mm}$ of exposed root surface area and was considered absent if the gingival margin was coronal to CEJ. All subjects were subjected to recall every six months and the measurements were recorded for statistical evaluation.

\section{Statistical analysis:}


The obtained clinical data were managed in Excel and then handed over to a statistical analysis which was carried out mainly by linearity testing and was performed using IBM Statistical Program for Social Sciences Version 17.0 (SPSS Inc., Chicago Illinois, USA). Changes were considered significant at the P $\leq$ 0.05. Depending on the depth of GR-time for individual teeth. The linearity of this dependence allows us to use a simple linear regression model $(Y=a+\beta x+\varepsilon)$ where $Y$ denotes depth, $x$ is the time and $\varepsilon$ is a random measurement error. We performed parameter estimates. Independence depths of time, we have formulated hypotheses using $\mathrm{HO}: \beta=0$, which would mean that any $\mathrm{x}$ would not affect the $\mathrm{Y}$.

\section{Results:}

A total of 53 subjects ( 33 females and 20 males) were included in the study.During the study period, a total of 673 teeth with gingival recession were evaluated. This number was distributed between the teeth in both maxillary and the mandibular jaws.

The highest mean depth of buccal recession within upper jaw was noted on first molars, premolar and canines. The least was noted on the incisors (Graph 1).

The highest mean depth of buccal recession within lower jaw was noted on premolars and canines. The least was noted on the incisors and second molars (Graph 2).

The result of analysis of progression in depth of GR is well documented in Table 1. It is remarkable to note that statistically significant change of depth in GR was seen on the following teeth: the mandibular first and second right premolar, mandibular right canine, left canine and left maxillary first molar ( $\mathrm{s} \leq$ 0.05 ) between the base line visit and the final follow up visit. But no statistically significant differences were found in rest of the teeth.It was interesting to note that there were overall 11 teeth that showed reversal in recession represented by negative sign that indicates improvement. 
Table 1

Regression analysis of recession depth according to the time

\begin{tabular}{|c|c|c|c|c|c|c|}
\hline \multirow[t]{2}{*}{$\begin{array}{l}\text { Number } \\
\text { of tooth }\end{array}$} & \multirow{2}{*}{$\begin{array}{l}\text { Linearity } \\
p- \\
\text { value }\end{array}$} & \multicolumn{2}{|c|}{$\begin{array}{l}\text { Regression } \\
\text { coefficient }\end{array}$} & \multirow{2}{*}{$\begin{array}{l}\mathrm{H}_{0}: \beta \\
=0 \\
\mathrm{p}- \\
\text { value }\end{array}$} & \multirow[t]{2}{*}{$\begin{array}{l}\text { \% variance } \\
\text {-explained }\end{array}$} & \multirow[t]{2}{*}{$\begin{array}{l}\text { Change of depth of recession } \\
\text { during } 3 \text { years }=\left(b^{\star 10}\right) \mathrm{mm}\end{array}$} \\
\hline & & A & B & & & \\
\hline 47 & 0.80 & 1.74 & 0.01 & 0.620 & 0.04 & 0.20 \\
\hline 46 & 0.89 & 2.11 & 0.002 & 0.910 & 8.00 & 0.04 \\
\hline 45 & 0.97 & 1.94 & 0.054 & $0.003^{\star}$ & 0.04 & 1.08 \\
\hline 44 & 0.91 & 2.06 & 0.05 & $0.006 *$ & 0.03 & 1.00 \\
\hline 43 & 0.93 & 2.29 & 0.069 & $0.003^{\star}$ & 0.05 & 1.38 \\
\hline 42 & 0.92 & 1.81 & 0.013 & 0.470 & 0.02 & 0.26 \\
\hline 41 & 0.885 & 1.776 & -0.006 & 0.671 & 0.08 & -0.12 \\
\hline 31 & 0.974 & 1.518 & 0.021 & 0.096 & 0.01 & 0.42 \\
\hline 32 & 0.96 & 1.62 & 0.003 & 0.270 & 0.01 & 0.06 \\
\hline 33 & 0.974 & 2.11 & 0.05 & $0.002^{\star}$ & 0.04 & 1.00 \\
\hline 34 & 0.99 & 1.91 & 0.031 & 0.080 & 0.01 & 0.62 \\
\hline 35 & 0.99 & 1.76 & 0.035 & 0.600 & 0.02 & 0.70 \\
\hline 36 & 0.76 & 1.64 & 0.001 & 0.940 & 5.00 & 0.02 \\
\hline 37 & 0.71 & 1.322 & 0.025 & 0.230 & 0.04 & 0.50 \\
\hline 27 & 0.181 & 1.408 & 0.035 & 0.132 & 0.05 & 0.70 \\
\hline 26 & 0.52 & 2.19 & 0.047 & $0.030 *$ & 0.02 & 0.94 \\
\hline 25 & 0.86 & 1.66 & -0.003 & 0.870 & 0.01 & -0.06 \\
\hline 24 & 0.43 & 2.08 & -0.009 & 0.630 & 0.01 & -0.18 \\
\hline 23 & 0.96 & 2.60 & -0.017 & 0.460 & 0.02 & -0.34 \\
\hline 22 & 0.96 & 1.63 & -0.005 & 0.710 & 0.06 & -0.10 \\
\hline 21 & 0.99 & 1.507 & -0.019 & 0.309 & 0.08 & -0.38 \\
\hline 11 & 0.96 & 1.04 & -0.003 & 0.239 & 0.08 & -0.06 \\
\hline 12 & 0.69 & 1.62 & -0.022 & 0.260 & 0.01 & -0.44 \\
\hline 13 & 0.86 & 2.42 & -0.003 & 0.860 & 0.01 & -0.06 \\
\hline
\end{tabular}




\begin{tabular}{|c|c|c|c|c|c|c|}
\hline \multirow[t]{2}{*}{$\begin{array}{l}\text { Number } \\
\text { of tooth }\end{array}$} & \multirow{2}{*}{$\begin{array}{l}\text { Linearity } \\
\text { p- } \\
\text { value }\end{array}$} & \multicolumn{2}{|c|}{$\begin{array}{l}\text { Regression } \\
\text { coefficient }\end{array}$} & \multirow{2}{*}{$\begin{array}{l}\mathrm{H}_{0}: \beta \\
=0 \\
\mathrm{p}- \\
\text { value }\end{array}$} & \multirow[t]{2}{*}{$\begin{array}{l}\text { \% variance } \\
\text {-explained }\end{array}$} & \multirow[t]{2}{*}{$\begin{array}{l}\text { Change of depth of recession } \\
\text { during } 3 \text { years }=(b * 10) \mathrm{mm}\end{array}$} \\
\hline & & A & B & & & \\
\hline 14 & 0.96 & 2.18 & -0.008 & 0.254 & 0.01 & -0.16 \\
\hline 15 & 0.98 & 1.87 & -0.011 & 0.510 & 0.03 & -0.22 \\
\hline 16 & 0.99 & 2.42 & 0.05 & 0.074 & 0.01 & 1.00 \\
\hline 17 & 0.803 & 1.748 & 0.014 & 0.625 & 0.05 & 0.28 \\
\hline
\end{tabular}

Canines showed the highest number in distribution of gingival recession recorded within upper jaw (Graph 3). Whereas the lower centrals, canines and the first premolars had the highest distribution of gingival recession recorded within lower jaw (Graph 4). Data regarding frequency, technique of tooth brushing and type of toothbrush showed that all patients included in this study used toothbrush (company unknown) to perform oral hygiene (Table 2). It is noted that the most of subjects (62.2\%) with GR at the first visit used hard toothbrush bristles, $22.7 \%$ of the subjects used medium bristles and only $22.7 \%$ used soft bristles.

Table 2

Data regarding frequency, technique of tooth brushing and type of toothbrush

\begin{tabular}{|c|c|c|c|c|c|c|c|c|}
\hline \multicolumn{3}{|c|}{ Toothbrush type } & \multicolumn{3}{|c|}{ Frequency of tooth brushing } & \multicolumn{3}{|c|}{ Toothbrushing technique } \\
\hline Type & Subject & $\%$ & & Subject & $\%$ & & Subject & $\%$ \\
\hline Soft bristle & 8 & $15.1 \%$ & One time & 9 & $16.9 \%$ & $\begin{array}{l}\text { Correct } \\
\text { method }\end{array}$ & 9 & 16.9 \\
\hline $\begin{array}{l}\text { Medium } \\
\text { bristle }\end{array}$ & 12 & $22.7 \%$ & $\begin{array}{l}\text { Two time } \\
\text { daily }\end{array}$ & 30 & $56.7 \%$ & \multirow[t]{2}{*}{$\begin{array}{l}\text { Incorrect } \\
\text { Method }\end{array}$} & \multirow[t]{2}{*}{44} & \multirow[t]{2}{*}{$83.1 \%$} \\
\hline $\begin{array}{l}\text { Hard } \\
\text { bristle }\end{array}$ & 33 & $62.2 \%$ & $\begin{array}{l}\text { Three time } \\
\text { daily }\end{array}$ & 14 & $26.4 \%$ & & & \\
\hline Total & 53 & 100 & Total & 53 & 100 & Total & 53 & 100 \\
\hline
\end{tabular}

The majority of the subjects (56.7\%) brushed their teeth twice daily, while $26.4 \%$ of the subjects brushed their teeth thrice daily whereas no more than $.5 \%$ of the subjects brushed their teeth once daily. Our data revealed that majority of subjects (88.6\%) at the first time of assessment did not know the correct technique of tooth brushing. However, less than $17 \%$ of the subjects knew about the correct tooth brush technique. 


\section{Discussion:}

GR is attributed to multiple etiological factors. Most of the studies that were designed to follow GR were either cross-sectional or had a short-term follow up. There is dearth of literature related to follow up of GR on a long term basis owing to the presence of confounding factors and the expense involved in designing a prospective cohort study. Our study can be considered one of the select few to have been designed for a long term follow up and simultaneous evaluation of the influence of tooth brushing on GR.

Our study included patients with an age range from 18-62 years that was relatively large with the purpose to evaluate the oral hygiene practices and their influence on recession in a wider age group. The questionnaire recorded at the commencement of the study revealed that the younger age group were more aware of the necessity of plaque control as could be judged by the high standard of oral hygiene and the frequency of brushing which was higher compared to the older age group.The frequency of brushing was checked at timely intervals and it was evident that the frequency remained unchanged in the younger age group; this was in accordance with Loe et al, ${ }^{18}$ who had reported no changes in the oral hygiene practices over years in his longitudinal study.

Various studies have displayed conflicting opinions of many authors on role of tooth brushing on GR. Some long-term studies negated the role of traumatic tooth brushing in the development of recession. ${ }^{19}$,

${ }^{20}$ Whereas others, however, report that frequency, type of toothbrush, and technique of tooth brushing have major role in the etiology of GR. ${ }^{15,28,29}$ To address this further, a systematic review by Rajapakse et $\mathrm{a}^{23}$ tried to address whether factors associated with tooth brushing predict the development and progression of non-inflammatory gingival recession through an extensive presentation of studies between 1996 to 2005.They concluded thatdata to support or refute the association between tooth brushing and GR are inconclusive.

Our longitudinal study validated two observations. First, whether improper tooth brushing and poor oral hygiene contributed to GR.Second, whether a corrective tooth brushing technique and good oral hygiene maintenance supported by professional plaque control in these patients of interest would prevent any further progression of GR.

The results of our study strongly correlate tooth brushing with GR. There was substantial proof from the observations from the questionnaire in our study which revealed that $62.2 \%$ of the affected subjects used a hardtooth brush. It was evident that use of hard brush lead to recession, this was in accordance with the results of Khocht et al, ${ }^{15}$ Daprile, ${ }^{7}$ Que et al ${ }^{22}$ and Chrysanthakopoulos. ${ }^{5}$ Further analysis of the results revealed that most of these subjects $(56.7 \%, 26.4 \%)$ brushed their teeth two or three time daily.Increased brushing frequency contributed to a higher percentage of recession in these subjects, this was in accordance with the findings from the studies by Vehkalahti et $\mathrm{al}^{29}{ }^{29}$ Kocht et $\mathrm{al}^{15}$ and Chrysanthakopoulos. ${ }^{6}$ 
An important observation of importance in our study was the relation of the tooth brushing technique and recession. It was found that the majority of the subjects (83.1\%) present with gingival recession at the baseline did not know the correct technique of toothbrushing and most of them as revealed by the questionnaire were using the horizontal scrub method. This method of brushing lead to increased recession was supported by the findings from the studies by Daprile, ${ }^{7}$ Tezel et al, ${ }^{28}$ and Lafzi et al. ${ }^{16}$

With regard to our study, data was collected to analyze the distribution of GR.It was found that gingival recession was more pronounced at maxillary and mandibular canines, premolars, mandibular incisors, maxillary first molars and Maxillary premolars. These areas represented low plaque scores with a high standard of oral hygiene. This distribution pattern seen in our study had similarities with the results observed in studies by Löe et al ${ }^{18}$ and Serino et al, ${ }^{24}$ in which it was significantly found that buccal GR were found at canines, molars, premolars and mandibular incisors.

The present study further analyzed the role of corrective tooth brushing technique on GR. All the subjects enrolled in our study were instructed on proper oral hygiene including correct tooth brushing technique (Modified Stillman technique) together with the thorough elimination of gingivitis through professional plaque control. The results of our longitudinal analysis reveal thatthose subjects with buccal recession evident in the first visit who maintained high standard of oral hygiene as per our instructions, it was observed that GR progressed only at the following teeth: the first and second right lower premolars, right lower canines, left lower canines and first upper left molars (total 17. 9\%). Nevertheless, depth of GR increased slightly within 3 years (max. $1.38 \mathrm{~mm}$ ), which, in our opinion, is not clinically significant.

An unusual observation seen in our study was that certain teeth that exhibited GR at the baseline visit displayed a slight improvement with reversal/regression of recession at the final visit.This decrease in the recession might be attributed to the creeping attachment/enhanced keratinization. This was the result of gingival massaging performed by the subjects instructed as part of the oral hygiene instructions, resulting in reduced inflammation, similar to the results in a study by Dorfman et al, ${ }^{9}$ who concluded that patients who exhibited GR would not develop further progression of GRif inflammation was controlled. The disappearance of recession might also have been made possible due to diagnostic/procedural errors in recording the CEJ in subsequent visits. Increased percentage of recession in canines could have been the result of recording of the perikymata, which resembles the CEJ and the presence of pseudo GR exaggerating the position of the gingival margin without any prominent root exposure, especially in the lower canines. ${ }^{26}$

A point of relevance is that our study had considered important factors such as type of tooth brush, tooth brushing frequency and tooth brushing technique but was not aimed at investigating the other variables, such as force of brushing and the use of either manual or electronic brushes responsible for recession. A systematic review by Heasman et al ${ }^{30}$ investigated the best available evidence associating and correlating all the variables associatedwith tooth brushing in the initiation of GR, and they concluded that the data to associate tooth brushing and GR remained largely inconclusive. 
One of the major limitations of the study was the use of Miller's classification of GR. Though Miller's classification is widely used in most of the studies, it has certain drawbacks.

\section{Conclusion:}

Based on the results achieved from our study we conclude thatfactors such as toothbrushing technique, type of toothbrush and toothbrushing frequency did have a contributory role in the etiology of GR.Further relevant observation in our study was; a well performed and well maintained oral hygiene, including a correct tooth brushing technique contributes significantly to the prevention of further progression of GR.

\section{Declarations}

\section{Conflict of interest and source of funding:}

The authors report no conflict of interest related to present study, and the study was self funded.

The manuscript has been read and content approved by all the authors. All the requirements for authorship have been met by the authors and the manuscript represents honest work by all the authors.

\section{References}

1. Al-Wahadni A, Linden GJ. Dentine hypersensitivity in Jordanian dental attenders. A case control study. J Clin Periodontol. 2002;29(8):688-93.

2. Arowojolu MO. Gingival recession at the University College Hospital, Ibadan-prevalence and effect of some etiological factors. Afr J Med Sci. 2000;29(3-4):259-63.

3. Banting DW, Ellen RP, Fillery ED. Prevalence of root surface caries among institutionalized olderpatients. Community Dent Oral Epidemiol. 1980;8(2):84-8.

4. Calsina G, Ramon JM, Echeverria JJ. Effects of smokingon periodontal tissues. J Clin Periodontol. 2002;29(8):771-6.

5. Chrysanthakopoulos NA. Aetiology andseverity of gingival recession in an adult populationsample in Greece. Dent Res J (Isfahan). 2011;8(2):64-70.

6. Chrysanthakopoulos NA. Prevalence and associated factors of gingival recession in Greek adults. J Investig Clin Dent. 2013;4(3):178-85.

7. Daprile G, Gatto MR, Checchi L. The evolution of buccal gingival recessions in astudent population: a 5-year follow-up. J Periodontol. 2007;78(4):611-4.

8. Dentino AR, Derderian G, Wolf M, Cugini M, Johnson R, Van Swol RL, et al. Six-month comparison of powered versus manual tooth brushing for safety and efficacy in the absence of professional instruction in mechanical plaque control. J Periodontol. 2002;73(7):770-8.

9. Dorfman HS, Kennedy JE, Birad WC. Longitudinal evaluation of free autogenous gingival grafts. A four year report. J Periodontol. 1982;53(6):349-52. 
10. Gorman WJ. Prevalence and etiology of gingival recession. J Periodontol. 1967;38(4):316-22.

11. Guinard EA, Caffesse RG. Treatment of localized gingival recessions. Part I. Lateral sliding flap. J Periodontol. 1978;49(7):351-6.

12. Heasman PA, Holliday R, Bryant A, Preshaw PM. Evidence for the occurrence ofgingival recession and non-carious cervical lesions as a consequence of traumatictoothbrushing. J Clin Periodontol. 2015;42(Suppl. 16):237-55.

13. Källestal C, Uhlin S. Buccal attachment loss in Swedish adolescents. J Clin Periodontol. 1992;19(7):485-91.

14. Kassab MM, Cohen RE. The etiology and prevalence ofgingival recession. J Am Dent Assoc. 2003;134(2):220-5.

15. Khocht A, Simon G, Person P, Denepitiya JL. Gingival recession in relation to history of hard toothbrush use. J Periodontol. 1993;64(9):900-5.

16. Lafzi A, Abolfazli N, Eskandari A. Assessment of the etiologic factors of gingivalrecession in a group of patients in northwest Iran. J Dent Res Dent Clin Dent Prospects. 2009;3(3):90-3.

17. Lawrence HP, Hunt RJ, Beck JD. Three-year root caries incidence and risk modeling in older adults in North Carolina. J Public Health Dent. 1995;55(2):69-78.

18. Löe $H$, Anerud A, Boysen $H$. The natural history of periodontal disease in man: Prevalence, severity, and extent of gingival recession. J Periodontol. 1992;63(6):489-95.

19. Litonjua LA, Andreana S, Bush PJ, Cohen RE. Tooth brushingand gingival recession. Int Dent J. 2003;53(2):67-72.

20. McCracken GI, Heasman L, Stacey F, Swan M, Steen N, de Jager M, et al. The impact of powered and manual tooth brushing on incipient gingival recession. J Clin Periodontol. 2009;36(11):950-7.

21. Pradeep K, Rajababu P, Satyanarayana D, Sagar V. Gingival recession: review and strategies in treatment of recession. Case Rep Dent. 2012;2012:563421.

22. Que K, Guo B, Jia Z, Chen Z, Yang J, Gao P. A cross-sectional study: non-carious cervical lesions, cervical dentine hypersensitivity and related risk factors. J Oral Rehabil. 2013;40(1):24-32.

23. Rajapakse PS, McCracken GI, Gwynnett E, Steen ND, Guentsch A, Heasman PA. Does tooth brushing influence the development and progression of non-inflammatory gingival recession? A systematic review. J Clin Periodontol. 2007;34(12):1046-61.

24. Serino G, Wennström JL, Lindhe J, Eneroth L. The prevalence and distribution of gingival recession in subject with high standard of oral hygiene. J Clin Periodontol. 1994;21(1):57-63.

25. Smith RG. Gingival recession. Reappraisal of an enigmaticcondition and a new index for monitoring. J Clin Periodontol. 1997;24(3):201-5.

26. Stoner JE, Mazdyasna S. Gingival recession in the lower incisor region of 15-year-old subjects. J Periodontol. 1980;51(2):74-6.

27. Susin C, Haas AN, Oppermann RV, Haugejorden O, Albandar JM. Gingival recession epidemiology and risk indicators in a representative urban Brazilian population. J Periodontol. 2004;75:1377-86. 
28. Tezel A, Canakci V, Cicek Y, Demir T. Evaluation of gingival recession in left- and right-handed adults. Int J Neurosci. 2001;110(3-4):135-46.

29. Vehkalahti M. Occurrence of gingival recession in adults. J Periodontol. 1989;60(11):599-603.

\section{Figures}

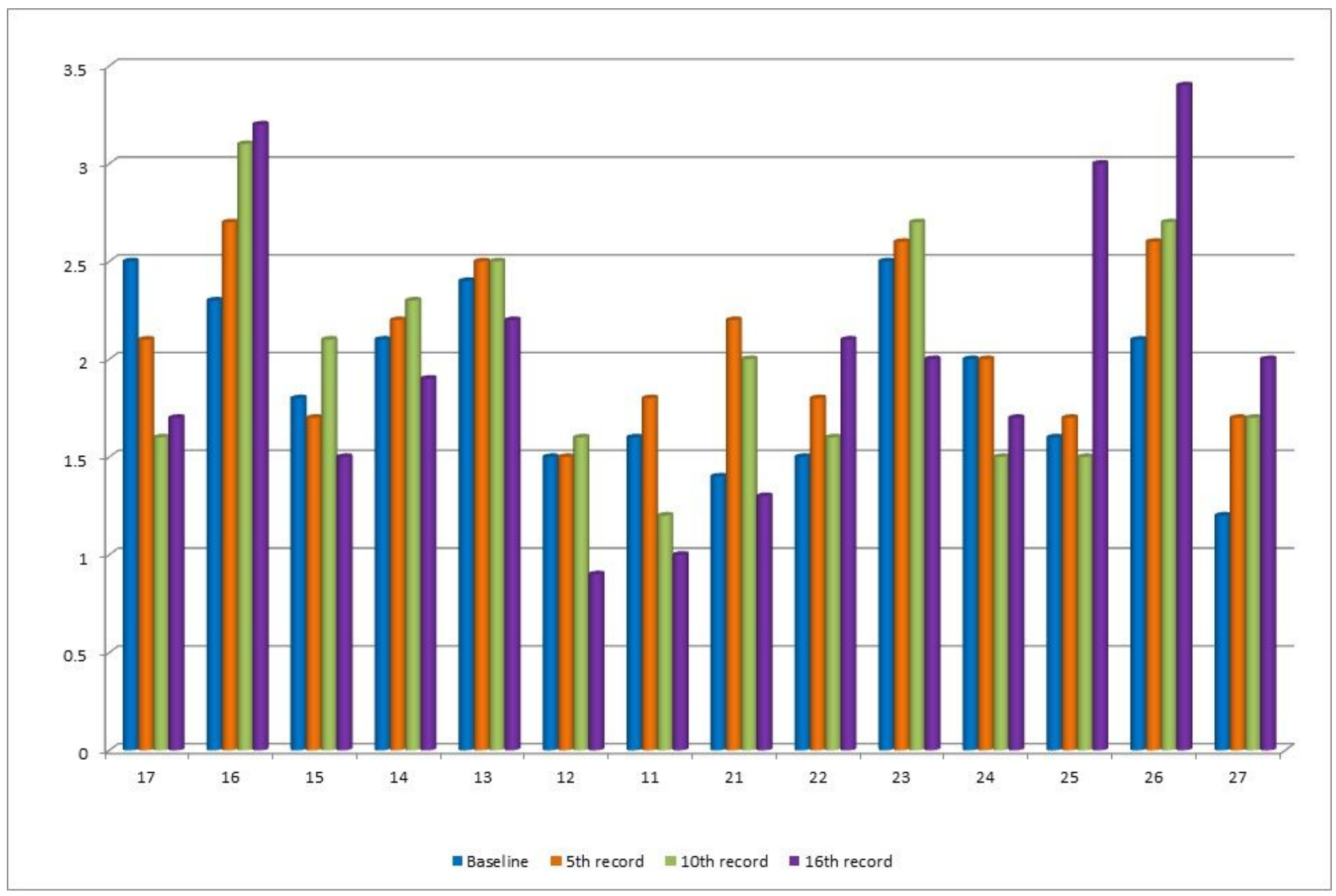

Figure 1

Mean depth of buccal recession within upper jaw 


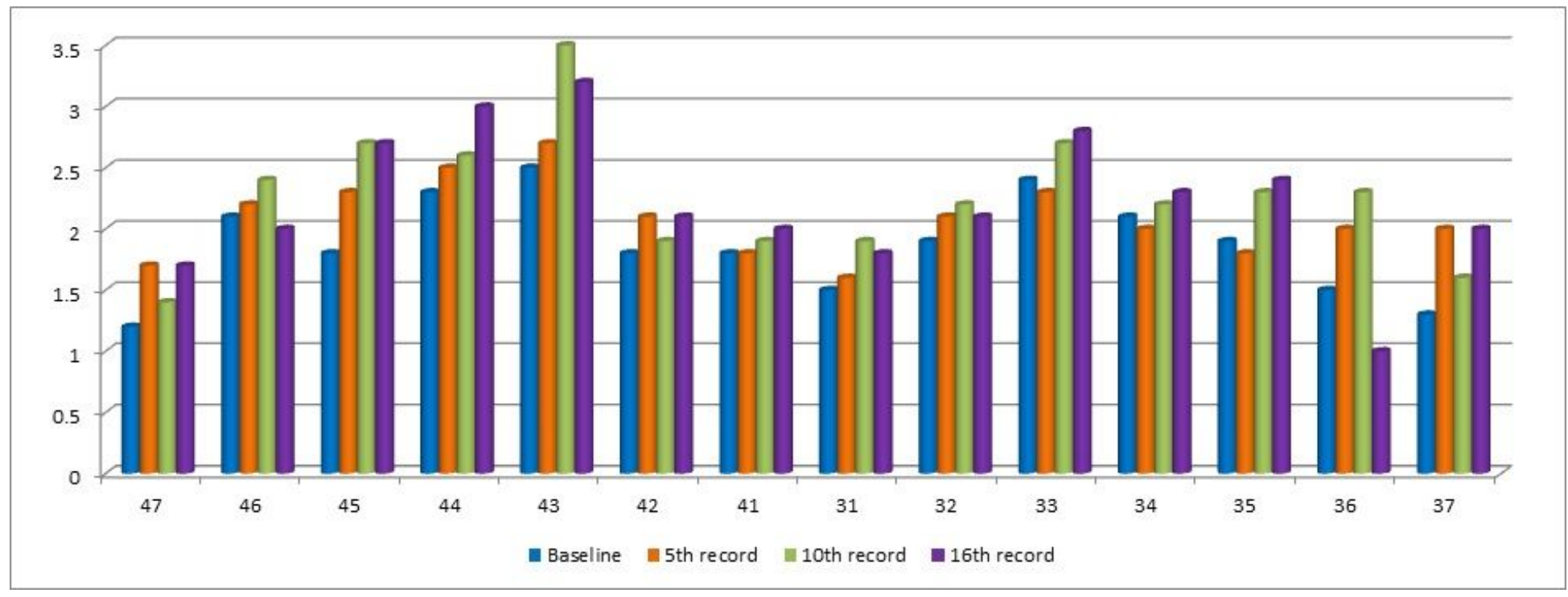

Figure 2

The mean depth of buccal recession within lower jaw

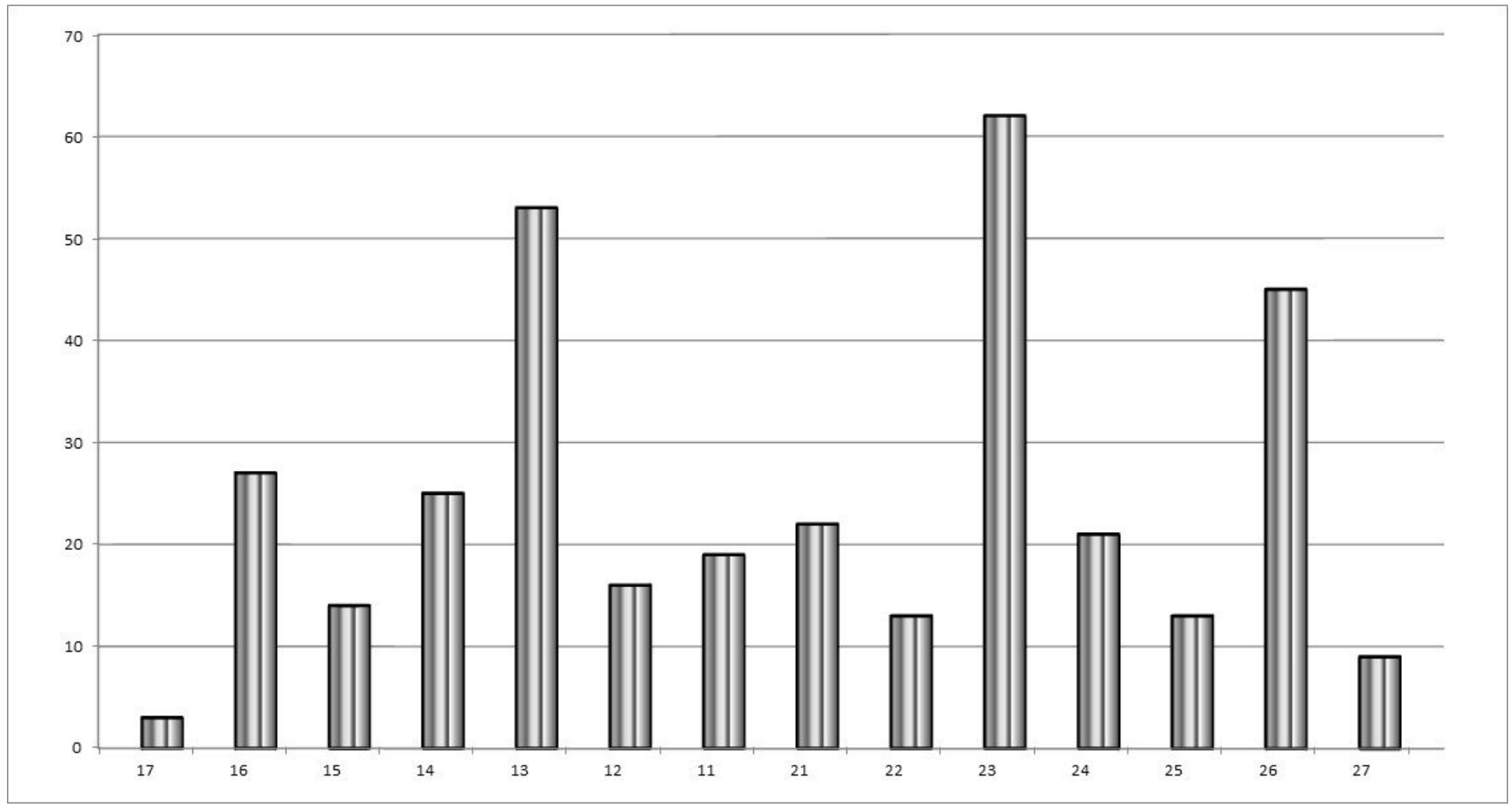

Figure 3

Distribution of gingival recession in the upper jaw 


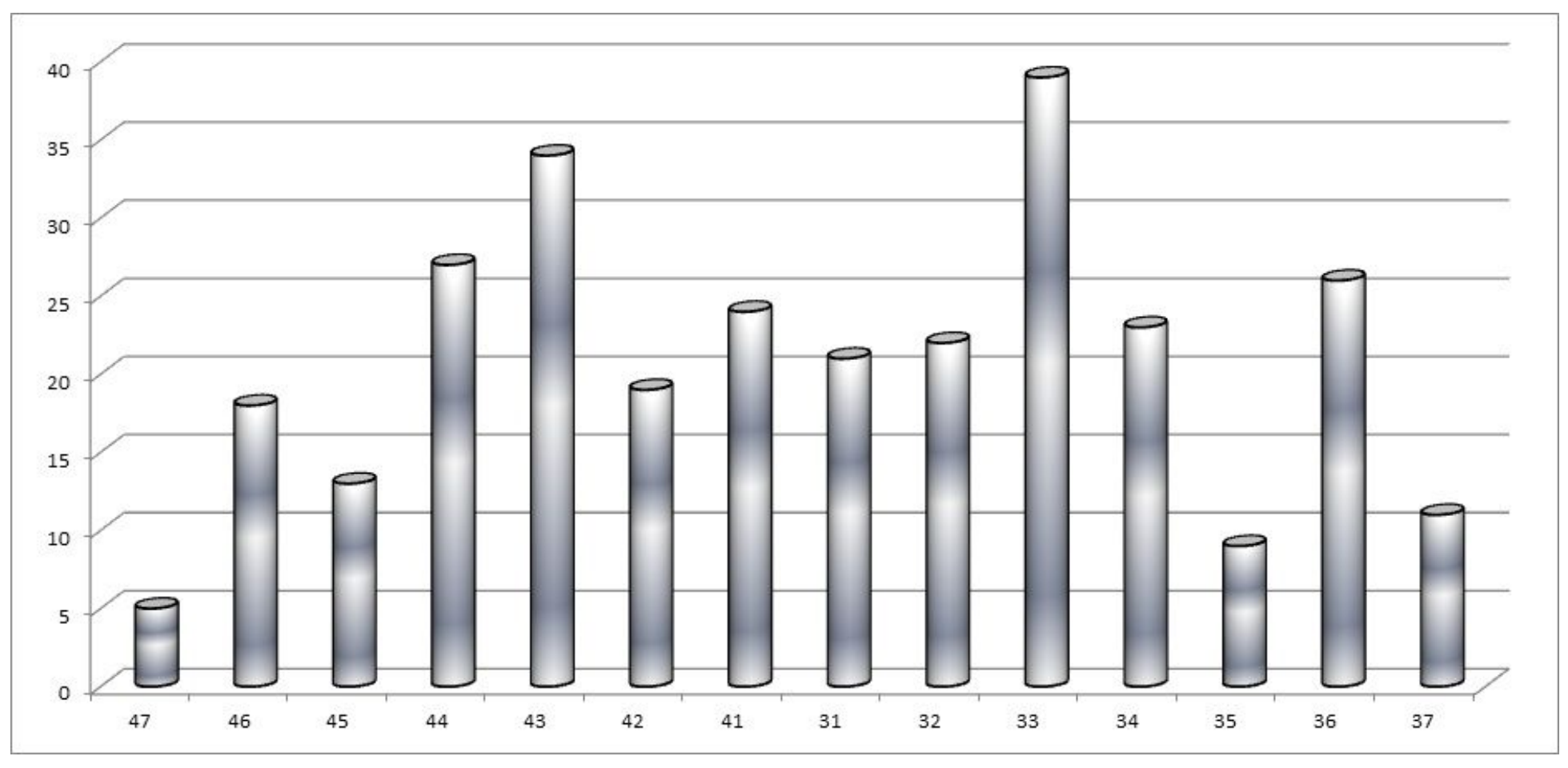

Figure 4

Distribution of gingival recession in the lower jaw 